\title{
Abnormal Electroretinograms and Visual Evoked Potentials in Chronic Papilledema Using Time-Difference Analysis
}

\author{
T. H.KIRKHAM and S.G. COUPLAND
}

SUMMARY: Visual function is usually considered to be normal in papilledema. We report previously undescribed $a b$ normalities in the electroretinograms (ERG) and visual evoked potentials (VEP) of two patients with chronic papilledema. The steady-state latencies of the ERG and VEP were calculated using time-difference analysis. The ERG was abnormal under both scotopic (slow) and photopic (fast) flicker

RESUME: Pour la première fois, nous décrivons des anomalies de l'électrorétinogramme (ERG) et des potentiels évoqués visuels (VEP) chez deux sujets avec oedème papillaire chronique. Nous avons calculé la latence de L'ERG et du VEP à l'état stable en utilisant une technique qui analyse la différence temporale entre les pics des courbes sinusoidales provoquées par la stimulation de papillotements sous conditions photopiques et scotopiques et de la stimulation elle-même. Ainsi, nous avons conditions, but the VEP was abnormal only to fast flicker photopic stimulation. This may indicate a relative vulnerability of a high frequency signal system under conditions of raised intracranial pressure. The abnormalities resolved rapidly once the intracranial pressure had been normalised. The cause of the VEP and particularly the ERG abnormalities remains unknown.

remarqué une latence prolongée de l'ERG sous conditions de papillotements lents (scotopique) et rapides (photopique); cependant le PEV était anormal seulement sous conditions photopiques. Peut-être existe-til lors d'hypertension intracranienne, une anomalie d'un système visuel à haute fréquence. Les anomalies de la latence sont devenues normales dès que la haute pression intracranienne fut normalisée. On ignore actuellement la vraie cause de ces anomalies.
From the McGill University Departments of Ophthalmology, Neurology and Neurosurgery and the Department of Neuro-Ophthalmology at the Montreal Neurological Hospital.

Reprint requests to T.H. Kirkham, MD. 3801 Université, Suite 20I, Montréal, Québec, Canada H3A 2B4.

\section{INTRODUCTION}

Marked papilledema from raised intracranial pressure without associated visual loss may be present for years. Visual disturbances in papilledema usually take the form of transient visual obscurations lasting only a few seconds affecting one or both eyes and often related to postural changes. True visual loss may however occur in papilledema. The pathogenesis of nerve fibre bundle loss is readily understood on the basis of ischaemic changes occurring in the prelaminar region of the swollen optic nerve (Hayreh, 1977a) which explains the classically described constriction of visual fields, development of arcuate scotomas and even sudden blindness (Rush, 1980), which is often a result of the sudden lowering of intracranial pressure by a neurosurgical procedure (Keane, 1974).

Reports of electrophysiological studies on patients with papilledema are rare. Hayreh (1977a) mentioned one patient whose electroretinogram (ERG) was normal. Korol and Stangos (1972) found the visual evoked potentials (VEP) to be normal and Halliday and Mushin (1980) stated that in their experience the VEP in papilledema had a normal wave form and latency. In raised intracranial pressure there are obviously diffuse pressure effects along the visual pathways from optic nerves to occipital areas. The appearance of the optic nerve head in papilledema is such a striking clinical abnormality that it is surprising that electrophysiological abnormalities have not been reported.

Recording of steady-state potentials evoked by a continuing train of flickering light stimulation produces a 
sinusoidal wave form in which individual responses cannot be related to any particular flash (Regan, 1972). A method has been described to measure the latencies of the steadystate ERG and VEP to the separate flashes of a flickering train of light (Diamond, $1977 \mathrm{a}, \mathrm{b}$ ). We have used this time-difference latency technique to estimate steady-state ERG and VEP latency to flickering light stimulation in patients with papilledema from raised intracranial pressure.

\section{CASE REPORTS}

Case 1 A 33 year old man experienced his first grand mal seizure 18 months before admission. Investigation showed a possible frontal falx meningioma, surgery was not advised and he was treated with diphenylhydantoin. Three more short seizures occurred. Two or three months before admission he noted episodes of wavy lines and intermittent flashes of light before the eyes lasting about 10 seconds each. His sense of smell deteriorated. Papilledema was detected which prompted further investigations.

The white cell count was $9300 / \mathrm{cu} \mathrm{mm}$ and sedimentative rate $30 \mathrm{~mm} / \mathrm{hr}$ (normal Wintrobe $0-20 \mathrm{~mm}$ ). The chest $\mathrm{x}$-ray was normal. Skull films showed hypertrophy of the crista galli and planum sphenoidale hyperostosis. CT scan showed a hyperdense region between the frontal poles and some abnormal vessels in the region of the mass arose from the left anterior meningeal artery.

Neurological examination showed no abnormal signs other than papilledema and anosmia. Visual acuity was $20 / 20, \mathrm{Jl}$ and all Ishihara colour plates in each eye. Pupillary reactions were normal with no relative afferent pupillary defect and pupil cycle times of $820 \mathrm{msec}$. each side. Goldmann perimetry showed marked enlargement of the blind spots, but with normal size isopters to $\mathrm{I}_{4} \mathrm{e}$ and $\mathrm{I}_{2} \mathrm{e}$ targets. Ocular movements showed jerky pursuit with a little gaze paretic nystagmus which was attributed to his diphenylhydantoin therapy. No exophthalmos was present. Fundoscopy showed pronounced bilateral papilledema. Paton's folds were observed around the discs particularly temporally Some deep peripapillary retinal hemorrhages were present. Intraocular pressures were normal and there was no evidence of previous ocular inflammatory disease.

Shortly before surgery he began to suffer transient obstructions of vision. At craniotomy a firm, rubbery tumour attached to the falx extended into both frontal lobes in a butterfly manner. Histopathological examination showed several areas of granulomat ous tissue with Langhans giant cells and surrounding lymphocytes. No organisms were found on Zeihl-Neelsen, Giemsa, PAS and silver methanamine stains. Treatment with rifampin and isoniazid was started. Mantoux skin test was. strongly positive at 48 hrs. Following surgery he stated that his vision rapidly became "brighter" but no difference in any clinical parameters of visual function could be detected. Over the next 6 weeks the papilledema disappeared.

Electrophysiological tests of visual function were undertaken 3 days before surgery and on three occasions following reduction of intracranial pressure.

Comment: A presumptive diagnosis of falx tuberculoma was made although there was no personal or family history of tuberculosis. Histology supported this idea, but no organisms were found and no growth was obtained on culture. The rapid resolution of papilledema following reduction of intracranial pressure was consistent with the idea that the disc appearance was the result of the raised intracranial pressure rather than infiltrative disease of the optic nerves by granuloma as may occur in sarcoidosis (Kirkham 1973).

Case 2 A 52 year old woman noticed intermittent horizontal diplopia in February 1980 , one month after a routine eye examination when new glasses were ordered. The diplopia came and went, lasting 20 minutes at a time. By the end of March she had permanent diplopia and became ataxic. She saw many doctors, lost 50 pounds and gradually became unable to walk. In August 1980 examination revealed gross papilledema. There were no transient obscurations of vision.

Corrected acuity was 20/25, $\mathrm{Jl}$ and all Ishihara colour plates in each eye. The pupil reactions were normal. Goldmann perimetry showed enormous blind spots with general constriction of isopters. There was a left VI paresis with an almost full range of abduction, but with a slowed abducting saccade. She had a primary position rotatory right beating nystagmus which was more marked on right gaze and absent on left gaze. Both fundi showed pronounced papilledema, the discs being extremely swollen and the retinae lifted up in concentric folds around the discs, particularly on the temporal sides. There were multiple hemorrhages and some yellow exudates on both discs. One could see right down the central cups to the cribrosa. No choroidal folds were seen.
Investigation showed a right cerebellar hemisphere tumour with distortion of the brain stem and obstruction of the fourth ventricle. Right cerebellar hemispherectomy was performed. Pathologically the tumour was hemangioblastoma. She made an excellent recovery. Electrophysiological tests were performed twice before surgery and on three occasions following normalisation of the intracranial pressure.

Comment: This patient had a cerebellar hemangioblastoma and there was no family history or other findings suggestive of Von Hippel-Lindau disease. The VI paresis disappeared immediately following surgery, the nystagmus was not visible 2 weeks later, her papilledema resolved over some 6 weeks and the visual field isopters improved to normal.

\section{ELECTROPHYSIOLOGICAL METHODOLOGY}

\section{Stimulation and recording}

Both scotopic and photopic averagedERGs and VEPs were simultaneously recorded. Electroretinal responses were recorded from infraorbital sites with $\mathrm{Ag}-\mathrm{AgCl}$ electrodes secured by hypoallergenic adhesive tape, while the VEPs were recorded from left $\left(0_{1}\right)$ and right $\left(\mathrm{O}_{2}\right)$ hemispheres. All active sites were referred to linked mastoids. ERGs can be reliably recorded using non-corneal electrodes and signalaveraging techniques. We have found in our laboratory that an infraorbital electrode placement records a steady state ERG with peak amplitude about $1 / 8$ that obtained by a corneal electrode and there is good correspondance in the two waveforms (Coupland, 1978, Gutrow-Tyler, Crews and Drasdo, 1978).

A Grass-PS-2 photic stimulator fitted with a Wratten 25 (red) filter was positioned $56 \mathrm{~cm}$. from the patient and masked to provide a 12 degree test field centered on a 40 degree surround which was maintained at $183 \mathrm{~cd} / \mathrm{m}^{2}$. For each recording trial in the photopic flicker condition the stimulation frequency was systematically increased in $5 \mathrm{~Hz}$ increments from 30 $50 \mathrm{~Hz}$. The test field luminance (when flickering at $50 \mathrm{~Hz}$ ) was $245 \mathrm{~cd} / \mathrm{m}^{2}$. In the scotopic flicker condition the patient was dark-adapted and binocularly viewed a $0.86 \mathrm{~cd} / \mathrm{m}^{2}$ blue (Wratten 47B filter) test-field flickering between $3-5 \mathrm{~Hz}$. 
The steady-state electroretinal and visual evoked responses were recorded with a Grass P511-J amplifiers (Grass Instruments Co.) and 256 samples were signal-a verged by an LSI-11 based multichannel analyser (TN1710, Tracor Northern Instruments Ltd) and stored on floppy disk.

\section{Steady-state latency determination}

For the photopic flicker condition, steady-state latency was determined by time-difference analysis (Diamond, 1977 a,b), which calculates steadystate latency as the time difference between corresponding points in the stimulus and ERG/VEP cycles. Peak reference points in each wave form were plotted on a two dimensional graph with flicker rate, expressed as interstimulus interval, on the ordinate and sweep duration on the abscissa (Fig. 1). Time-difference calculation of steady-state ERG/VEP latency by least-squares regression through peak reference points determined the abscissa intercept values. The mean of these abscissa intercept values defined the steady-state latency of the ERG/ VEP for the frequency range. Steadystate latency determined in this manner has been shown to be reliably recordable in this frequency range and the procedure can be automated on computer (Coupland, Taylor and Koopman, 1980).

Normative data has been obtained for 31 subjects under these flicker

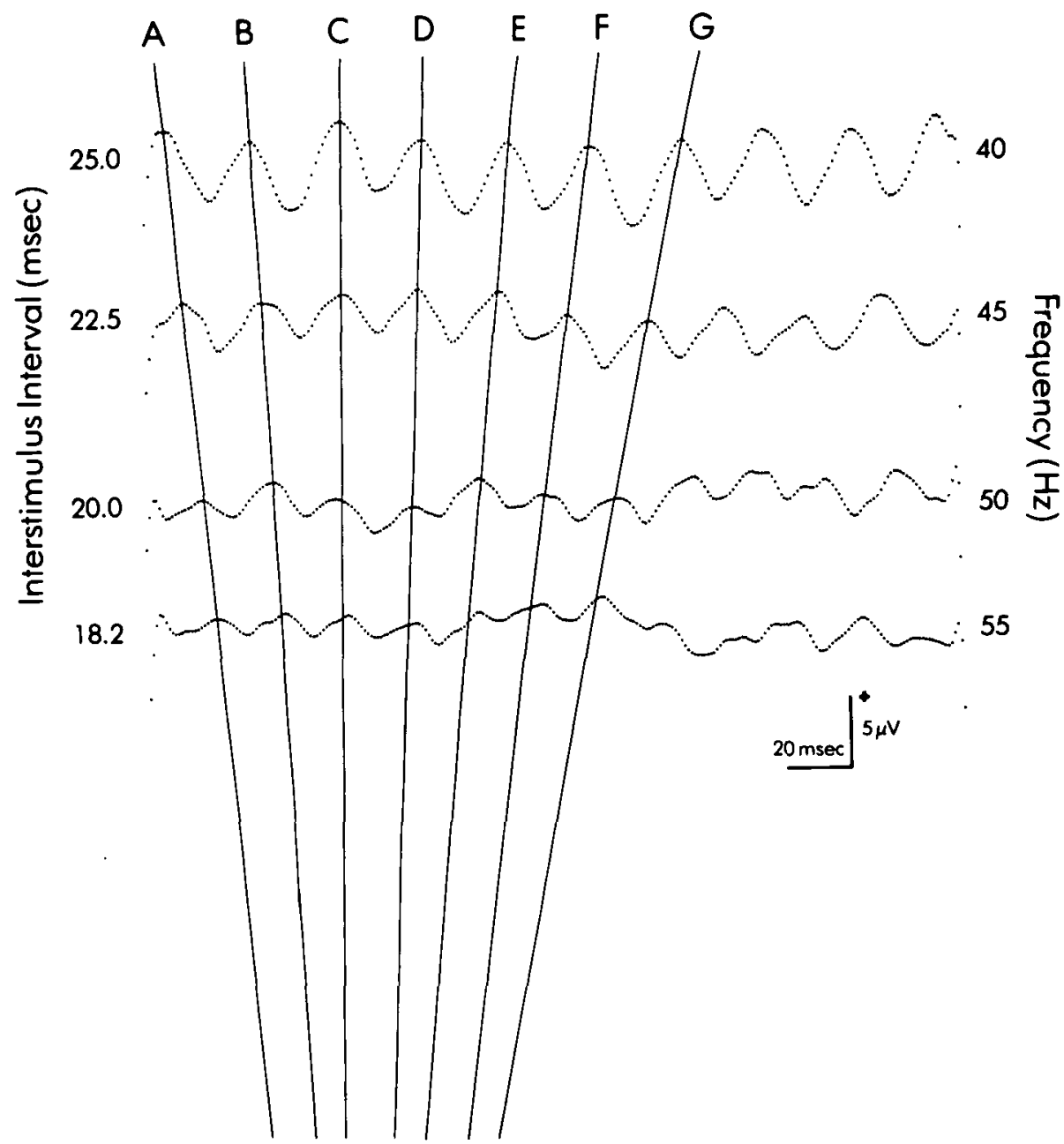

Figure 1-A family of our VEP waveforms recorded under photopic flicker conditions to illustrate time-difference latency calculation (Case 1). Each waveform represents a steady-state VEP to light flickering in the $40-55 \mathrm{~Hz}$ range. Vertical lines A - G are regression lines placed through peak reference features which converge to intercept the abscissa. The mean of the abscissa intercept values is taken as the steady-state VEP latency for this frequency range.

conditions ( 20 female, 11 male, ages 19 to 56 years) and their steady-state electroretinal and visual evoked potential latencies calculated using time-difference analysis. The mean ERG steady-state latency was $67 \pm 7$ msec for scotopic and $36 \pm 5 \mathrm{msec}$ for photopic flicker stimulation. The VEP steady state latencies were $110 \pm 9$ msec for scotopic and $63 \pm 4$ for photopic flicker stimulation.

For the purposes of this study we used the data from only one eye and one scalp site in the analysis of the steady-state ERG and VEP latencies. Since interocular and interhemispheric latency differences are negligible in the normal population for binocular stimulation we used the ERG and VEP recording sites from which waveforms were most clearly discernable for the latency analysis.

\section{RESULTS}

Table 1 shows that for case 1, the scotopic (slow) flicker condition and the ERG b-wave implicit time fell within normal limits by the 6 th post-op week (Fig. 2). Likewise, the VEP systematically decreased in steadystate latency, but it should be noted that all these values fell within normal population limits (Fig. 3). Under the photopic (fast) flicker conditions both steady-state ERG and VEP latencies were initially outside the $99 \%$ normal population limits. However, by the second post-operative week these latency values had fallen within normal limits and continued to decrease in latency until the sixth postoperative week.

Table 2 shows that the results of Case 2 are similar to Case 1. Under scotopic flicker conditions the b-wave ERG implicit time was delayed preoperatively but the VEP latency was within normal limits. Under photopic conditions, flicker steady state latencies of both ERG b-wave and VEP were abnormal when intracranial pressure was high, but quickly fell to normal limits post-operatively. 


\section{DISCUSSION}

Current concepts of the pathogenesis of papilledema in raised intracranial pressure derive largely from the work of Hayreh (1977b). Raised cerebrospinal fluid pressure in the intracranial subarchnoid space must be transmitted down an intact nerve sheath to
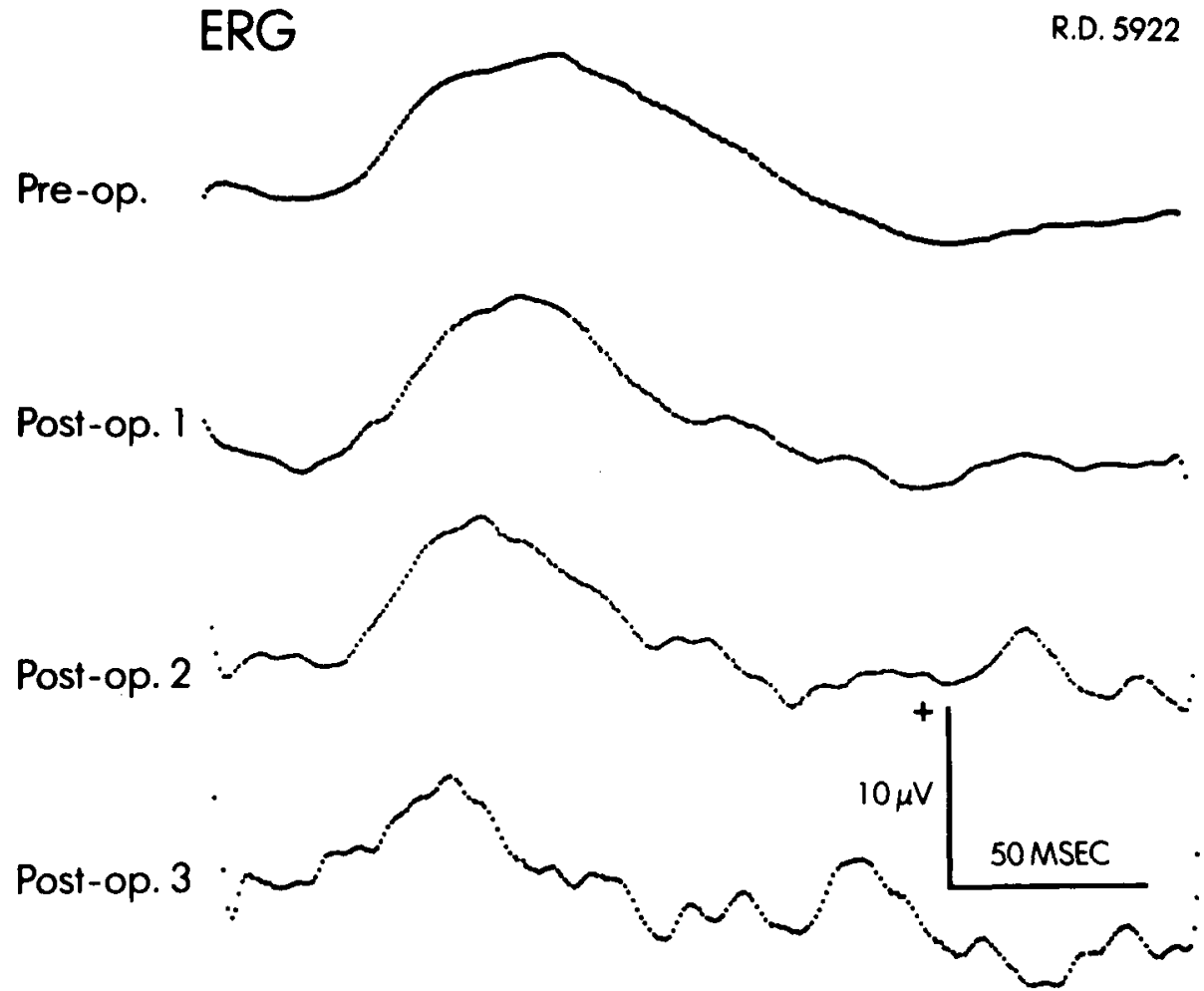

Figure 2- Averaged scotopic conditions ERG's of Case 1. Note steady significant decrease in b-wave implicit time in post-operative recordings.

\section{VEP}

R.D. 5922

Pre-op.
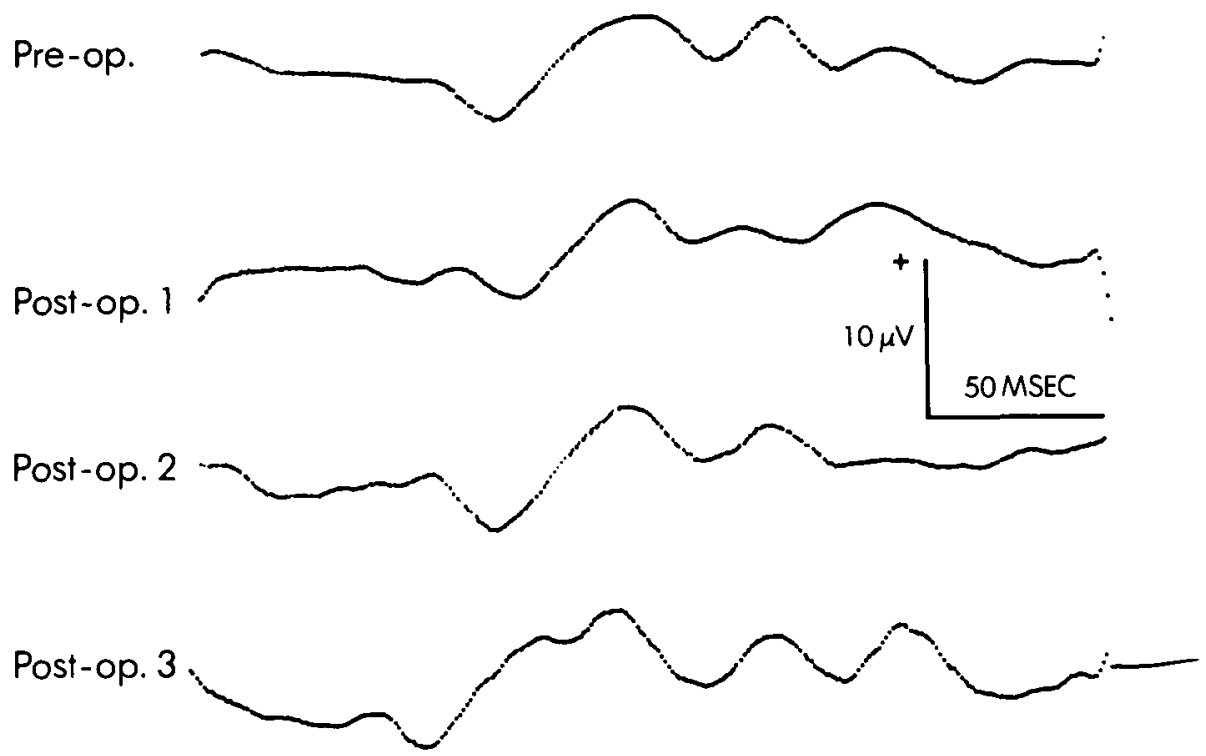

Figure 3-Scotopic averaged VEP's from Case 1. Note major positive component remains unchanged in pre and post-operative recordings unlike the change noted in the ERG (fig. 2).

produce a rise in tissue pressure in the optic nerve. The raised tissue pressure causes slowing of axoplasmic flow in the axons of the optic nerve with consequent intraaxonal accumulation of axoplasm in the prelaminar region of the optic nerve. This produces swelling of the optic disc and increased visibility of the nerve fibre bundles. Compression of thin walled venous channels results in venous stasis of the disc with secondary capillary dilatation. The later formation of microaneurysms and hemorrhages on and adjacent to the disc probably result from vascular endothelial damage from relative hypoxia due to circulatory slowing. The yellow exudates seen commonly in papilledema probably represent accumulations of axoplasm which leaks from damaged axons as a result of their disruption by a mixture of mechanical and ischaemic damage. Thus in papilledema, the primary factors are mechanical with secondary vascular phenomena. Hayreh (1977b) believed that slowed axoplasmic flow would not interfere with conduction of nerve impulses by the axon since this occurs along the axon membrane and thereby explained the normality of visual function in papilledema. Our electrophysiological studies show definite abnormalities of visual function despite clinically "normal" vision.

The scotopic steady-state visual evoked potential latency to $3-5 \mathrm{~Hz}$ flicker was not significantly delayed either pre or post operatively (Tables $1,2)$. There did appear to be a slight decrease in VEP latency over the testing period (fig. 1), but the latency values were within normal limits. However, under photopic conditions, the steady-state VEP latency response to fast $(30-50 \mathrm{~Hz})$ flicker stimulations was significantly delayed pre-operatively (Tables 1,2). Within a few days of lowering the high intracranial pressure, the VEP latency had returned to normal limits. It is interesting to note that only the fast steady-state VEP response was preoperatively abnormal. Under our laboratory conditions using timedomain analytic techniques (Diamond, $1977 \mathrm{a}, \mathrm{b})$, we have determined the steady-state latency of the VEP to 
TABLE I

Steady-state electroretinogram (ERG) and visual evoked potential (VEP) latency under scotopic and photopic flicker conditions for Case l.

\begin{tabular}{|c|c|c|c|}
\hline & Day of test + & $\begin{array}{c}\text { ERG latency } \\
\text { msec }\end{array}$ & $\begin{array}{c}V E P \text { latency } \\
\text { msec }\end{array}$ \\
\hline Scotopic & -3 & 92 & 125 \\
\hline $3-5 \mathrm{~Hz}$ & +3 & 83 & 121 \\
\hline \multirow[t]{2}{*}{ Flicker } & +10 & 70 & 122 \\
\hline & +32 & 62 & 118 \\
\hline 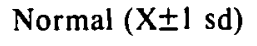 & & $67 \pm 7$ & $110 \pm 9$ \\
\hline Photopic & -3 & 52 & 78 \\
\hline $30-50 \mathrm{~Hz}$ & +3 & 50 & 62 \\
\hline \multirow[t]{2}{*}{ Flicker } & +10 & 50 & 61 \\
\hline & +32 & 41 & 60 \\
\hline Normal $(\mathrm{X} \pm 1$ sd) & & $36 \pm 5$ & $63 \pm 4$ \\
\hline
\end{tabular}

-Day of test - and + days before and after surgery.

TABLE II

Steady-state electroretinogram (ERG) and visual evoked potential (VEP) latency under scotopic and photopic flicker conditions for Case 2.

\begin{tabular}{|c|c|c|c|}
\hline & Day of testt & $\begin{array}{c}\text { ERG latency } \\
\text { msec }\end{array}$ & $\begin{array}{c}V E P \text { latency } \\
\text { msec }\end{array}$ \\
\hline Scotopic & -5 & 86 & 112 \\
\hline $3-5 \mathrm{~Hz}$ & -1 & 84 & 113 \\
\hline \multirow[t]{3}{*}{ Flicker } & +3 & 79 & 108 \\
\hline & +8 & 70 & 110 \\
\hline & +24 & 67 & 110 \\
\hline Normal $(\mathrm{X} \pm 1 \mathrm{sd})$ & & $67 \pm 7$ & $110 \pm 9$ \\
\hline Photopic & -5 & 55 & 75 \\
\hline $30-50 \mathrm{~Hz}$ & -1 & 53 & 77 \\
\hline \multirow[t]{3}{*}{ Flicker } & +3 & 49 & 67 \\
\hline & +8 & 42 & 62 \\
\hline & +24 & 39 & 62 \\
\hline Normal (X士1 sd) & & $36 \pm 5$ & $63 \pm 4$ \\
\hline
\end{tabular}

*Day of test - and + days before and after surgery.

intermittent photic stimulation in the $30-50 \mathrm{~Hz}$ frequency range to be $63 \pm$ $4 \mathrm{msec}$. for "normal" patient populations. Spekreijse, Estevez and Reits (1977) using frequency-domain analysis of steady-state evoked potentials to full field flicker identified three frequency component subsystems with different cortical origins in the human visual system. They described a high frequency signal system which dominates in the $40-60 \mathrm{~Hz}$ frequency range and appears to have an apparent latency of about $80 \mathrm{msec}$. The observed prolonged VEP latency to fast flicker in our patients might best be interpreted as evidence of selective damage to such a high frequency signal system of the optic nerve and retrochiasmal pathways.

Another interpretation of the observed steady-state VEP delay is based on Regan's (1968) model of high frequency flicker response. This model considers the evoked potential to be the outcome of an attenuation stage plus a real delay. It is possible that in papilledema this real delay remains constant and it is the shape of the attenuation function that changes so that there would be an observed change in the apparent steady-state latency.

We consider that the steady-state VEP abnormality results from a metabolic effect of the raised intracranial pressure on the visual pathways in general, but on the optic nerve head in particular, perhaps due to a relative ischemia. The latency abnormality rapidly improved post-operatively.

Our finding of abnormal ERGs in chronic papilledema is more puzzling. Flicker ERG implicit times were abnormally delayed under both scotopic and photopic flicker conditions suggesting that both rod and cone photoreceptor systems were involved. Delayed ERG implicit times were prolonged both pre-operatively, when intracranial pressure was high and, postoperatively, for almost 2 weeks. These striking abnormalities of steady-state electroretinal responses in papilledema are not easily explained. The ERG b-wave is generated by preganglionic retinal elements, probably arising from the Muller cells in the inner nuclear layer (Miller and Dowling, 1970). Macular changes (Morris and Sanders, 1980), peripapillary changes and extensive choroidal folds (Bird and Sanders, 1973) have been described in papilledema as well as peripheral retinal hemorrhages (Galvin and Sanders, 1980; Keane, 1981), but none were present in our patients. Perhaps there is some mechanical damage to Muller cells, photoreceptors or bipolar cells since there were well defined radial folds visible in the retinae around the enormously swollen discs. Possibly preganglionic retinal elements are affected by some trans synaptic factor as a result of the slowed axoplasmic flow in the nerve fibre layer. Disturbed retinal metabolism may also be present as a result of relative anoxia from either slowed arterial supply, choroidal or retinal, or from impaired venous drainage via the relatively strangulated central retinal vein (Rios-Montenegro, Anderson and David, 1973). The true cause of the electrophysiological abnormalities which we have described remains unknown. We have had the opportunity to examine 6 other patients with chronic papilledema and the abnormalities of ERG and VEP are consistent. We have not found any patient with chronic papilledema to be electrophysiologically "normal." 


\section{ACKNOWLEDGEMENTS}

This work was aided by grants from the Canadian National Institute for the Blind out of the E.A. Baker Foundation for Prevention of Blindness and the Multiple Sclerosis Society of Canada. Dr. S.G. Coupland is supported by a post-doctoral fellowship from the Multiple Sclerosis Society of Canada. We thank the W. Garfield Weston Foundation, the Stephen B. Roman Foundation and the Birks Family Foundation for their generous assitance towards the establishment of our visual neurophysiology laboratory. Miss Judy Bengle R.N. gave technical assistance.

\section{REFERENCES}

BIRD, A.C. and SANDERS M.D., (1973): Choroidal folds in association with papilloedema. Br. J. Ophthalmol., 57: 89-97.

COUPLAND, S.G., (1978): Time-domain analysis of steady-state electroretinal and visual evoked response to intermittent photic stimulation. Ph.D. thesis, Simon Fraser University.

COUPLAND, S.G., TAYLOR, M.J. and KOOPMAN, R.F., (1980): EEG landscapes: An application of computer cartography. Psychophysiology, 17: 413-417.

DIAMOND, A.L., (1977, a): Latency of the steady state visual evoked potential. Electroencephalog. Clin. Neurophysiol., 42: 125-127.

DIAMOND, A.L., (1977, b): Phase-versus-time analysis of the steady-state evoked potential latency. J. Opt. Soc. Amer., 67: 84l-842.
GALVIN, R, and SANDERS, M.D. (1980): Peripheral retinal haemorrhages with papilloedema. Br. J. Ophthalmol., 64: 262266.

GREEN, G.J., LESSELL, S. and LOEWENSTEIN, J.I., (1980): Ischemic optic neuropathy in chronic papilloedema. Arch. Ophthalmol., 98: 502-504.

GUTROW-TYLER, J.F., CREWS, S.J. and DRASDO, N., (1978): Electroretinography with noncorneal and corneal electrodes. Invest. Ophthalmol. Vis. Sci., 17: 1124-1127.

HALLIDAY, A.M. and MUSHIN, J., (1980): The visual evoked potential in neuro ophthalmology. In: Electrophysiology and psychophysics: their use in ophthalmic diagnosis. International Ophthalmology Clinics, 20: 155-183.

HAYREH, S.S., (1977a): Optic disc edema in raised intracranial pressure. VI Associated visual disturbances and their pathogenesis. Arch. Ophthalmol. 95: 1566-1579.

HAYREH, S.S., (1977, b): Optic disc edema in raised intracranial pressure. V Pathogenesis. Arch. Ophthalmol., 95: 1553-1565.

KEANE, J.R., (1974): Sudden blindness after ventriculography. Bilateral retinal vascular occlusion superimposed on papilloedema. Am. J. Ophthalmol., 78: 275-278.

KEANE, J.R., (1981): Papilledema with unusual ocular hemorrhages. Arch. Ophthalmol., 99: 262-263.

KIRKHAM, T.H., (1973): Neuro-ophthalmic presentations of sarcoidosis. Proc. Roy. Soc. Med., 66: 167-169.
KOROL, S. and STANGOS, N., (1972): Les potentiels évoqués corticaux dans les affections du nerf optique. Rev. Oto-NeuroOphtalmol, 44: 387-394.

MILLER, R.F. and DOWLING, J.E., (1970): Intracellular responses of the Muller cells of mudpuppy retina: their relation to " $b$ " wave of the electroretinogram. J. Neurophysiol., 33: 323-341.

MORRIS, A.T. and SANDERS, M.D. (1980): Macular changes resulting from papilloedema. Br. J. Ophthalmol., 64: 211-216.

REGAN, D., (1968): A high frequency mechanism which underlies visual evoked potentials. Electroenceph. clin. Neurophysiol., 25: 231237.

REGAN, D., (1972): Evoked potentials in Psychology, Sensory Physiology and Clinical Medicine. Chapman and Hale, London.

RIOS-MONTENEGRO, E.N., ANDERSON, D.R., and DAVID, N.J., (1973): Intracranial pressure and ocular hemodynamics. Arch. Ophthalmol., 89: 52-58.

RUSH, J.A., (1980): Pseudotumor cerebri. Clinical profile and visual outcome in 63 patients. Mayo Clin. Proc., 55: 541-546.

SPEKREIJSE, H., ESTEVEZ, $O$. and REITS, D., (1977): Visual evoked potentials and the physiological analysis of visual processes in man. In: Visual Evoked Potentials in Man: New Developments. (Desmedt, J.E. ed). Clarendon Press, Oxford, pp. 16-89. 